\title{
Tracing diagenetic smectite-to-illite transition using stable $K$ isotopes
}

\author{
Xin-Yuan Zheng ${ }^{1}$, Brian L. Beard ${ }^{2}$, W. Crawford \\ Elliott $^{3}$, Clark M. Johnson ${ }^{2}$ \\ ${ }^{1}$ Department of Earth and Environmental Sciences, University \\ of Minnesota-Twin Cities, Minneapolis MN 55455, \\ USA (zhengxy@umn.edu) \\ ${ }^{2}$ Department of Geoscience, University of Wisconsin- \\ Madison, Madison WI 53706, USA \\ ${ }^{3}$ Department of Geosciences, Georgia State University, \\ Atlanta GA 30302, USA
}

The smectite-to-illite (S-to-I) transition is a ubiquitous diagenetic process in argillaceous sediments at low to moderate temperatures. Several major elements (e.g., K, Mg, $\mathrm{Fe}, \mathrm{Si}$ ) are transferred between clays and ambient fluids, this transition, therefore, has exerted significant controls on global cycles of these elements. In addition, because diagenetically formed illites have been shown to be amenable to $\mathrm{K}(\mathrm{Ar})-\mathrm{Ar}$ dating, this reaction has been useful in constraining thermal history of a sedimentary basin and history of ore formation associated with certain mineral deposits, such as porphyry $\mathrm{Cu}$ deposits and MVT $\mathrm{Pb}-\mathrm{Zn}$ deposits. Despite its importance, direct tracing of sources and suppiles of key elements involved in the S-to-I reaction remains lacking, leaving large uncertainty in estimating its reaction kinetics in field.

Here we explore the utility of stable $\mathrm{K}$ isotopes $\left({ }^{41} \mathrm{~K} /{ }^{39} \mathrm{~K}\right.$ or $\delta^{41} \mathrm{~K}$ ) in tracing the S-to-I transition using represenative samples from two sedimentary basins with known burial and diagenetic histories (the Denver Basin and Disturbed Belt). All S-to-I samples analyzed were separated from bentonite layers to avoid influence of detrital clays, and were well charaterized for their mineralogy and K-Ar ages. In the Denver Basin, a large spread in $\delta^{41} \mathrm{~K}$ values ranging from $1.2 \%$ to $0 \%$ o (relative to NIST 3141a) was observed, with higher $\delta^{41} \mathrm{~K}$ values corresponding to samples with higher degree of illitization (\%I). Such variabilty cannot be ingored if high-precision $\mathrm{K}(\mathrm{Ar})-\mathrm{Ar}$ dating is concerned. Because \% $\mathrm{I}$ generally increased with burial depths in this basin, a broad linear correlation between $\delta^{41} \mathrm{~K}$ values and depths was observed, with an exception for samples associated with an abnormally high geothermal gradient in the basin. In marked constrast, $\delta^{41} \mathrm{~K}$ values of samples from the Disturbed Belt were clustered around $\sim-0.4 \%$ with limited variability, even that the analyzed samples represented a large range of $\% \mathrm{I}$ from $\sim 25 \%$ to $90 \%$. The distinct behavior of $\mathrm{K}$ isotopes in the two sedimentary basins can be explained via a water-rock interaction model. Our study provides the first demonstration that $\mathrm{K}$ isotopes can be powerful tracers to directly constrain conditions of diagenetic smectite-to-illite transition. 